\title{
Ciliary Neurotrophic Factor and Stress Stimuli Activate the Jak- STAT Pathway in Retinal Neurons and Glia
}

\author{
Ward M. Peterson, Quan Wang, Roumiana Tzekova, and Stanley J. Wiegand \\ Regeneron Pharmaceuticals, Tarrytown, New York 10591
}

Ciliary neurotrophic factor (CNTF) is pleiotrophic for central, peripheral, and sensory neurons. In the mature retina, CNTF treatment enhances survival of retinal ganglion and photoreceptor cells exposed to otherwise lethal perturbation. To understand its mechanism of action in vivo, the adult rat retina was used as a model to investigate CNTF-mediated activation of Janus kinase/signal transducer and activator of transcription (Jak-STAT) and ras-mitogen activated protein kinase (rasMAPK). Intravitreal injection of Axokine, an analog of CNTF, phosphorylates STAT3 and MAPK and produces delayed upregulation of total STAT3 and STAT1 protein in rat retina. Activated STAT3 is predominantly localized in nuclei of retinal Müller (glial) cells, ganglion cells, and astrocytes, but not in photoreceptors. Although CNTF $\alpha$-receptor (CNTFR $\alpha$ ) mRNA and protein are localized predominantly if not exclusively in retinal neurons, coincident CNTF-mediated STAT3 signaling was observed in both glia and neurons. CNTF-induced activation of Jak-STAT signaling prompted us to investigate STAT3 phosphorylation after a variety of stress-mediated, conditioning stimuli. We show that STAT3 is activated in the retina after exposure to subtoxic bright light, mechanical trauma, and systemic administration of the $\alpha_{2}$-adrenergic agonist xylazine, all of which have been shown previously to condition photoreceptors to resist light-induced degeneration. These results demonstrate that CNTF directly stimulates Jak-STAT and ras-MAPK cascades in vivo and strongly suggest that STAT3 signaling is an underlying component of neural responsiveness to stress stimuli. The observation that CNTF activates STAT3 in ganglion cells, but not in photoreceptors, suggests that Jak-STAT signaling influences neuronal survival via both direct and indirect modes of action.

Key words: ciliary neurotrophic factor; signal transducer and activator of transcription; Müller cell; ganglion cell; glial fibrillary acidic protein (GFAP); mitogen-activated protein kinase; extracellular receptor kinase; neuroprotection; conditioning
The mature nervous system responds to sublethal environmental stress and injury by mounting a self-protective mechanism that enhances neuronal survival in the face of subsequent insult. For example, retinal photoreceptors in albino rats can be conditioned to resist the damaging effects of prolonged exposure to constant light if animals are previously exposed to a conditioning period of nondamaging, bright light (Liu et al., 1998). This phenomenon of conditioning in photoreceptors and other neurons is thought to involve stress-mediated release of growth factors and cytokines and subsequent activation of intracellular signaling pathways (Mattson and Scheff, 1994). Ciliary neurotrophic factor (CNTF) is one such neurocytokine with pleiotrophic actions in the developing and mature nervous system (Adler et al., 1979; Sendtner et al., 1994; Segal and Greenberg, 1996). CNTF is a cytosolic protein that lacks a consensus sequence for secretion and has been postulated to act as an injury-activated factor under pathological conditions (Lin et al., 1989; Stockli et al., 1989). Normally localized inside Schwann cells, CNTF can be detected extracellularly after sciatic lesion (Sendtner et al., 1992). In mature retina, CNTF is upregulated in vivo in response to a variety of stressmediated conditions (Cao et al., 1997; Liu et al., 1998; Ju et al.,

\footnotetext{
Received Nov. 5, 1999; revised March 6, 2000; accepted March 17, 2000.

We thank Drs. George Yancopoulos and John Rudge for their assistance and guidance in the experimentation, and Evan Burrows and Claudia Murphy for contributing their expertise to the design of the figures. We also acknowledge the Regeneron community for supporting the present study.

Correspondence should be addressed to Ward Peterson or Stanley Wiegand, Regeneron Pharmaceuticals, 777 Old Saw Mill River Road, Tarrytown, NY 10591. E-mail: stan.wiegand@regpha.com.

Copyright (C) 2000 Society for Neuroscience $\quad 0270-6474 / 00 / 204081-10 \$ 15.00 / 0$
}

1999). Exogenous CNTF protects mature neurons in the CNS and peripheral nervous system from degeneration arising from multiple etiologies (LaVail et al., 1992; Sendtner et al., 1992; Hagg and Varon, 1993; Anderson et al., 1996).

CNTF binds to its $\alpha$-receptor (CNTFR $\alpha$ ) and two signaltransducing transmembrane subunits, LIFR $\beta$ and gp130, thus specifically activating the Janus tyrosine kinase/signal transducers and activators of transcription (Jak-STAT) signaling pathway (Stahl et al., 1994; Stahl and Yancopoulos, 1994). The activated CNTF receptor complex preferentially phosphorylates STAT3 at residue Y705 and to a lesser extent STAT1 at Y701, thus promoting homodimerization or heterodimerization of STAT3 and STAT1 and subsequent nuclear translocation of dimerized STAT proteins (Bonni et al., 1993; Wegenka et al., 1993; Darnell et al., 1994). CNTFR $\alpha$ is tethered to the plasma membrane by glycosylphosphatidylinositol linkage and can be released from the cell, particularly under pathological conditions. Soluble CNTFR $\alpha$ can bind CNTF and signal via the LIFR $\beta /$ gp130 heterodimer in vitro (Davis et al., 1993); CNTFR $\alpha$ may therefore, under some conditions, function as a soluble mediator of the effects of CNTF in vivo. Although CNTFR $\alpha$ mRNA is expressed predominantly, if not exclusively, by neurons in the normal developing and mature brain and retina (Kirsch and Hofmann, 1994; MacLennan et al., 1996; Kirsch et al., 1997; Fuhrmann et al., 1998), cellular localization of CNTF-mediated activation of the Jak-STAT pathway has not been demonstrated in vivo. In the present study, the adult rat retina was used as a model system to investigate CNTF- and stress-mediated Jak-STAT signaling in neurons and glia.

The involvement of the ras-mitogen activated protein kinase 
(MAPK) pathway in response to CNTF administration was also investigated at the cellular level in the present study and compared with Jak-STAT signaling. We show that STAT3 is activated in both retinal neurons and glia, whereas p42/44 MAPK is activated only in retinal glia. Additionally, we demonstrate that a variety of stress-mediated, conditioning stimuli also activate JakSTAT signaling in mature retina.

\section{MATERIALS AND METHODS}

Protein and antibodies. The potency of human CNTF is increased by substituting glutamine at position 63 with an arginine (Panayotatos et al., 1993). Additionally, C-terminal truncations of up to 27 amino acids of CNTF were found to be at least as active as full-length CNTF (Negro et al., 1994). Axokine is a modified version of human CNTF in which the $\mathrm{C}$ terminus has been truncated by 15 residues, the free cysteine has been replaced with an alanine, and the glutamine at position 63 has been switched to an arginine. Axokine is three to five times more potent than the CNTF parent molecule as measured by in vitro neuronal survival assays and in vivo studies and has improved stability properties over CNTF. Polyclonal antibodies against CNTF were raised by immunizing rabbits with whole Axokine protein. Antibodies from bleeds were affinity purified and used in immunoblots at a dilution of $\sim 1 \mu \mathrm{g} / \mathrm{ml}$ and were shown to cross-react with endogenous rat CNTF in Western blots and immunocytochemistry. Immunoblots were performed with commercially available antibodies for STAT3 and Tyr705-phosphorylated STAT3 (pSTAT3), STAT1 and Tyr701-phosphorylated STAT1 (pSTAT1), and p44/42 MAPK and Thr202/Thr204 phospho-p44/42 MAPK (pMAPK) (New England Biolabs, Beverly, MA). Immunocytochemical studies were performed with the same STAT3 and pSTAT3 antibodies. Additional immunocytochemical studies used a monoclonal Cy3-conjugated anti-glial fibrillary acidic protein (GFAP) and a monoclonal anti-S-100 ( $\beta$-subunit) (Sigma, St. Louis, MO).

Animal handling and surgery. Male Sprague Dawley rats, 10-14 weeks of age, were used in all experiments. Animals were entrained in a $12 \mathrm{hr}$ light/dark cycle with an in-cage illuminance of $<25$ foot-candles for at least $5 \mathrm{~d}$ before experiments. Unless otherwise specified, animals were anesthetized with an intraperitoneal injection of a mixture of chloral hydrate and pentobarbital (CPB) $(260 \mathrm{mg} / \mathrm{kg}$ chloral hydrate and 50 $\mathrm{mg} / \mathrm{kg}$ sodium pentobarbital by body weight). Axokine or vehicle $(10 \mathrm{~mm}$ phosphate buffer) was injected $(1 \mu \mathrm{l})$ into the vitreal cavity of the rat eye using a Hamilton (Reno, NV) microliter syringe attached to a beveled 32 gauge Hamilton needle. The injection was made by inserting the needle through the sclera $\sim 0.3 \mathrm{~mm}$ posterior to the limbus near the superior pole of the eye and guiding the needle $\sim 1.5 \mathrm{~mm}$ into the vitreal cavity at an angle that avoids the lens. This injection procedure also avoided penetration of and trauma to the neural retina. Animals were killed by either intracardial overdose of anesthesia or exanguination of deeply anesthetized animals, transcardial perfusion of heparinized $0.9 \% \mathrm{NaCl}$ Ringer's solution, followed immediately by rapid, ice-cold perfusion in PBS containing 4\% paraformaldehyde. All experiments on animals were conducted in accordance with the Policy on the Use of Animals in Neuroscience Research.

Conditioning protocols. Retinas were assayed for STAT3 activation in response to three separate stress-mediated, conditioning protocols that have been shown previously to protect photoreceptors from the damaging effect of prolonged bright light. The first conditioning stimulus involved the exposure of animals to a period of subtoxic bright light that does not damage the retina but activates an endogenous neuroprotective mechanism in photoreceptors (Liu et al., 1998). In brief, rats were brought in-house, entrained for 1-2 weeks, and then exposed to 125-150 foot-candles for either 24 or $48 \mathrm{hr}$ before returned to normal cyclic lighting conditions for up to 1 week. Retinas were collected immediately and at 1,3 , and $7 \mathrm{~d}$ after exposure to the conditioning period of bright light. In a second conditioning paradigm, the retina was mechanically injured by inserting a 30 gauge needle through the sclera and directly into the retina at $\sim 1-2 \mathrm{~mm}$ posterior to the pars plana in the superior hemisphere. After mechanical injury, animals were then returned to normal cyclic lighting conditions for $7 \mathrm{~d}$ before being killed. In a third conditioning protocol, each animal was given a single intraperitoneal injection of ketamine alone $(42 \mathrm{mg} / \mathrm{kg})$, xylazine alone $(8.4 \mathrm{mg} / \mathrm{kg})$, or ketamine-xylazine combination $(42 \mathrm{mg} / \mathrm{kg}$ ketamine and $8.4 \mathrm{mg} / \mathrm{kg}$ xylazine). Previous work has shown that daily intramuscular injections of the $\alpha_{2}$-adrenergic agonist xylazine for $4 \mathrm{~d}$ significantly attenuates photo- receptor damage caused by subsequent exposure to $7 \mathrm{~d}$ of constant light (Wen et al., 1996).

Immunoblot analysis. Fresh retinas were harvested immediately after the animals were killed, snap frozen in liquid nitrogen, and stored at $-80^{\circ} \mathrm{C}$. Retinas were homogenized in lysis-phosphatase inhibitor buffer containing: $20 \mathrm{~mm}$ Tris-HCl, $2 \mathrm{~mm}$ EGTA, $150 \mathrm{~mm} \mathrm{NaCl}, 2 \mathrm{~mm} \mathrm{Na}_{3} \mathrm{VO}_{4}$, $1 \mu \mathrm{M}$ okadaic acid, $50 \mathrm{~mm} \mathrm{NaF}, 1 \% \mathrm{NP}-40,5 \mu \mathrm{g} / \mathrm{ml}$ leupeptin, $10 \mu \mathrm{g} / \mathrm{ml}$ aprotinin, $2 \mu \mathrm{g} / \mathrm{ml}$ pepstatin-A, and $1 \mathrm{~mm}$ PMSF. Protein levels were quantified using BCA protein assay (Pierce, Rutherford, IL). Total protein of $50 \mu \mathrm{g}$ from each sample was electrophoresed (Mini-Protean II system; Bio-Rad, Hercules, CA) on polyacrylamide gels and transferred to nitrocellulose membranes (Stratagene, La Jolla, CA). For STAT3/ pSTAT3, STAT1/pSTAT1, and MAPK/pMAPK paired immunoblots, protein samples were loaded in duplicate on separate gels and immunoblotted under identical conditions. All of the primary antibodies were applied at 1:1000 dilution. Signals were visualized using a Photope-HRP Detection Kit for Western Blotting Signals (New England Biolabs). Signal was quantified by conventional densitometric analysis (NIH Image software).

Immunohistological analysis. Retinal sections were stained for STAT3, pSTAT3, MAPK, pMAPK, GFAP, and S-100 ( $\beta$-subunit) antigen. Eyes were cryoprotected with $30 \%$ sucrose, frozen and embedded in TissueTEK OCT compound (Miles, Elkhart, IN), cryosectioned (10 $\mu \mathrm{m})$, and mounted onto Probe-on Plus glass slides (Fisher Scientific, Pittsburgh, PA). For the mechanically injured eyes, care was taken to ensure that retinal sections included the region surrounding the site of focal injury. Retinal sections were stained for STAT3, pSTAT3, MAPK, pMAPK, GFAP, and S-100 antigen, all at a dilution of 1:200. Biotinylated goat anti-rabbit IgG (Vector Laboratories, Burlingame, CA) was used as secondary antibody (diluted 1:1000), and staining was completed using an avidin-biotin-peroxidase (ABP) complex reaction (Vectastain Elite ABC kit; Vector Laboratories). The peroxidase was visualized with diaminobenzidine as the chromagen. For double-labeling experiments using S-100 antigen and pSTAT3, sections were first processed for pSTAT3 and visualized using the ABP method, and then reblocked and stained for S-100 antigen. S-100 labeling was visualized with a Cy3-conjugated sheep anti-mouse IgG antibody (diluted 1:200; Sigma).

\section{RESULTS}

\section{Axokine-induced phosphorylation of STAT3 and STAT1 in total rat retina}

Antibodies that recognize total STAT3 and Y705-phosphorylated STAT3 (pSTAT3) were used for immunoblotting homogenized rat retina. Expression of total STAT3 or pSTAT3 was evaluated at time points ranging from $5 \mathrm{~min}$ to $7 \mathrm{~d}$ after a single intravitreal injection of Axokine $(1 \mu \mathrm{g})$ or vehicle (10 mM phosphate buffer), or after administration of anesthesia (CPB) alone (Fig. 1A). STAT3 is normally inactive but can be phosphorylated as early as 15 min after an injection of Axokine. The levels of phosphorylated STAT3 increased over the following $2 \mathrm{~d}$ and disappeared by $4 \mathrm{~d}$. Intravitreal injection of vehicle resulted in only slight phosphorylation of STAT3, beginning 1-4 hr after the injection and persisting for $16 \mathrm{hr}$. A similar pattern of pSTAT3 activation was seen in the anesthesia control group. An increase in total STAT3 protein was observed only in the Axokine-treated group. This increase in total STAT3 is evident by $16 \mathrm{hr}$, most pronounced at $2 \mathrm{~d}$, and is maintained for at least 1 week (Fig. $1 C$ ). This secondary increase in total and unphosphorylated STAT3 levels may be mediated by the earlier robust phosphorylation of STAT3.

Membranes that were immunoblotted with either STAT3 or pSTAT3 antibodies were stripped and reprobed for CNTF and Axokine using a polyclonal antibody that recognizes both proteins (Fig. 1B). Axokine could be detected in retinal samples between the 5 min and $2 \mathrm{~d}$ time points, which is coincident with the appearance of the pSTAT3 bands in the Axokine-treated retinas in Figure $1 A$. No apparent changes in the levels of endogenous CNTF were observed in any of the three treatment groups.

Total STAT1 and Y701-phosphorylated STAT1 (pSTAT1) pro- 


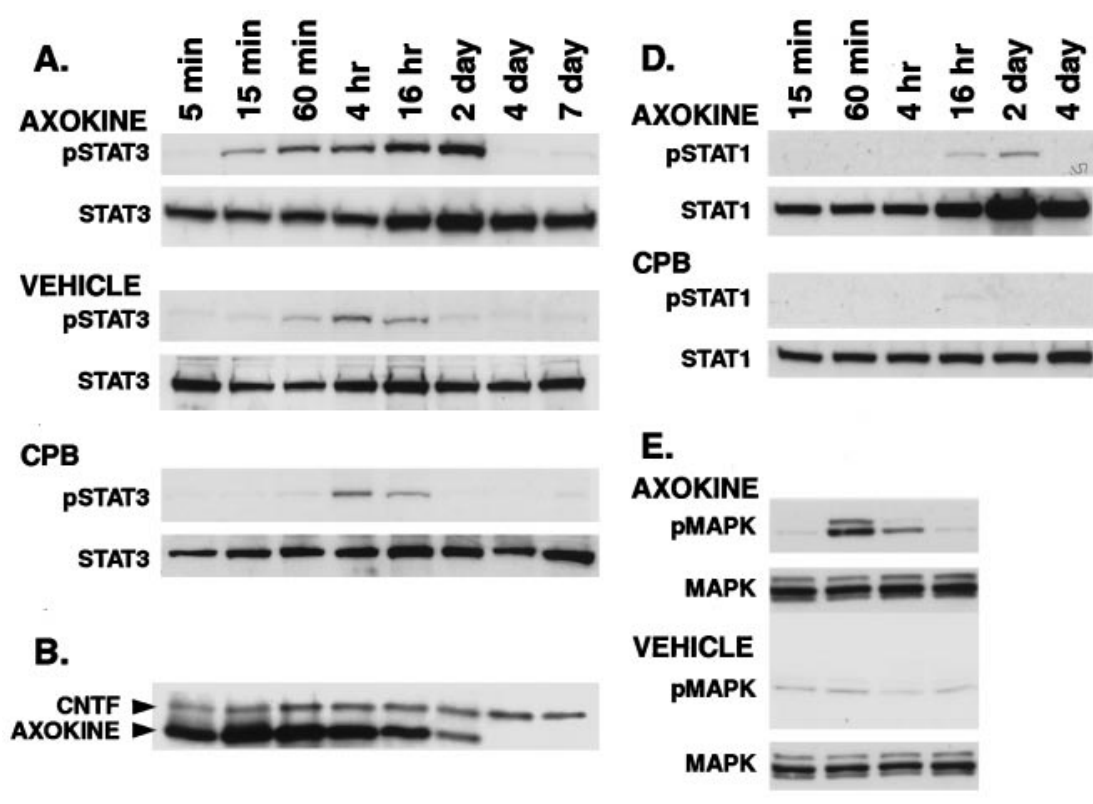

C.

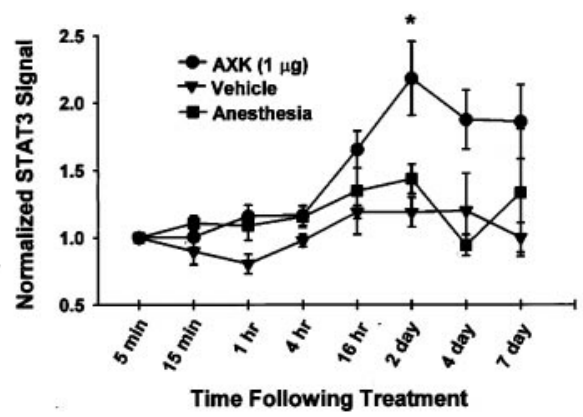

Figure 1. Effects of Axokine on phosphorylated and total STAT3, STAT1, and MAPK in homogenized rat retinas. $A$, Retinas were harvested at various times indicated ( $5 \mathrm{~min}$ to $7 \mathrm{~d}$ ) after a single intravitreal injection of Axokine. Homogenized retinas were Western blotted $(50 \mu \mathrm{g} /$ lane $)$ to detect total STAT3 and Y705phosphorylated STAT3 (pSTAT3). The band size for both STAT3 and pSTAT3 is the expected $92 \mathrm{kDa}$. Axokine produced robust pSTAT3 signal beginning at $15 \mathrm{~min}$ and disappearing by $4 \mathrm{~d}$. Weaker and more transient pSTAT3 signals were seen in the vehicle and anesthesia (CPB) control groups. $B$, Membranes from Axokinetreated STAT3/pSTAT3 immunoblots were stripped and reblotted using an antibody that recognizes both CNTF and Axokine ( 23 and $21 \mathrm{kDa}$, respectively). Axokine was detected in the retina for up to $2 \mathrm{~d}$ after injection. $C$, Graph summarizing the time-dependent effects of total STAT3 for each treatment group. STAT3 signal was quantified at each time point using conventional densitometric analysis and normalized to the STAT3 signal at $5 \mathrm{~min}$. Analysis of immunoblots from time course studies culled from three separate groups of animals shows a significant increase in normalized STAT3 signal in the Axokine-treated group ( $p<0.05$; repeated ANOVA, Dunnett's post hoc $t$ test). Error bars are in terms of SE. $D$, Immunoblots for total STAT1 and Y701-STAT1 (pSTAT1) were performed on Axokine-treated and anesthesia control retinas. Axokine weakly activated pSTAT1 at the later time points but dramatically increased total STAT1 levels by $16 \mathrm{hr}$. E, Western blots for total MAPK and pMAPK for Axokine-treated retinas showed robust transient activation of MAPK at $60 \mathrm{~min}$. teins were also immunoblotted by using antibodies that discriminated between these forms of STAT1. Although STAT1 is normally present in retinal homogenates, Axokine injection did not result in immediate phosphorylation of STAT1 (Fig. 1D). However, a small of amount of pSTAT1 was detected at $16 \mathrm{hr}$ and $2 \mathrm{~d}$ after Axokine treatment, with lower levels also $16 \mathrm{hr}$ after anesthesia alone. Although we saw no phosphorylation of STAT1 at the earlier time points, Axokine nevertheless produced a delayed, but marked, increase in total STAT1. As for total STAT3, an increase in total STAT1 protein was noted by $16 \mathrm{hr}$, peaked at $2 \mathrm{~d}$, and persisted through day 7 in the Axokine group.

The ras-MAPK pathway represents a distinct intracellular signaling cascade that has been shown previously to be activated in the nervous system by a variety of neurotrophic factors, including the nerve growth factor family of neurotrophins, and by a variety of stress-mediated stimuli (Segal and Greenberg, 1996). To determine whether CNTF activates the ras-MAPK pathway, we used antibodies that discriminate between total and phosphorylated p44/42 MAPK (pMAPK) to detect activated p44/42 MAPK after Axokine injection. Immunoblotting results for Axokine- and vehicle-treated control retinal homogenates are shown in Figure $1 E$. Axokine treatment produced a much more robust phosphorylation of MAPK at 60 min than vehicle treatment, and by $4 \mathrm{hr}$, pMAPK signal was significantly reduced.

Our results indicate that a single intravitreal injection of Axokine activates two principal tyrosine kinase signaling pathways in the retina, Jak-STAT and ras-MAPK. Axokine produced robust
STAT3 phosphorylation within 15 min of injection, which persisted for at least $2 \mathrm{~d}$. Axokine did not activate STAT1 until the $16 \mathrm{hr}$ time point. Delayed upregulation of total STAT1 and STAT3 also was observed after Axokine injection but not under control conditions. Termination of both STAT1 and STAT3 phosphorylation signals after $2 \mathrm{~d}$ is coincident with clearance of Axokine from the retina. In contrast, Axokine-dependent phosphorylation of MAPK was observed only at the $1 \mathrm{hr}$ time point, and no change in the levels of total MAPK was observed throughout the duration of the study.

\section{Immunolocalization of basal and activated total STAT3}

At $15 \mathrm{~min}$ after vehicle injection, light diff use staining of total STAT3 was observed in the ganglion cell layer (GCL), in radial processes within the inner plexiform layer (IPL), in a few cell bodies of the inner nuclear layer (INL), and laterally throughout the outer plexiform layer (OPL) (Fig. 2A). Similar patterns of STAT3 immunoreactivity were observed in untreated eyes (results not shown).

As early as $15 \mathrm{~min}$ after Axokine injection, a change in the distribution of total STAT3 could be observed in a limited region of the retina: (1) appearance of dense staining of nuclear profiles along the inner limiting membrane (ILM) and nerve fiber layer (NFL) in which retinal astrocytes are localized; (2) increased labeling of retinal ganglion cell bodies; and (3) appearance of dense labeling of scattered cell bodies and nuclei within the INL (Fig. 2B). In other cryosections from the same eye, a coincident 


\section{STAT3}
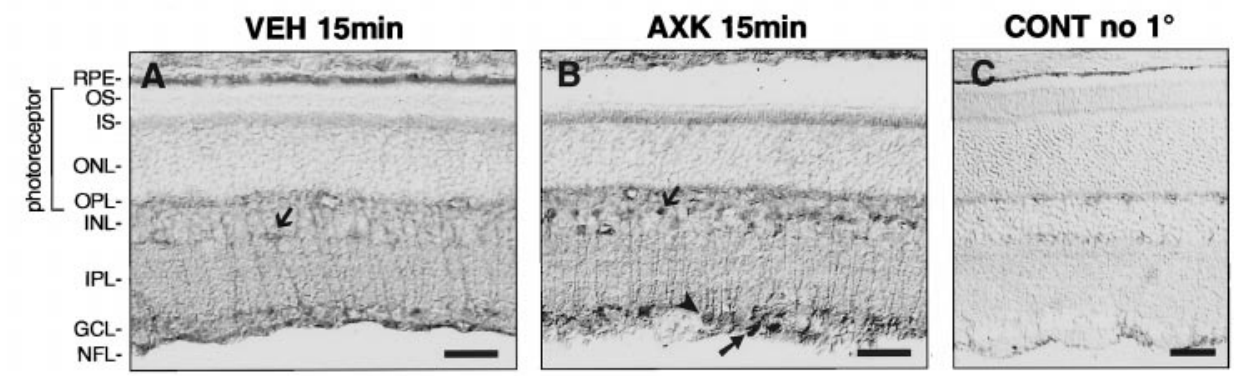

AXK 30min

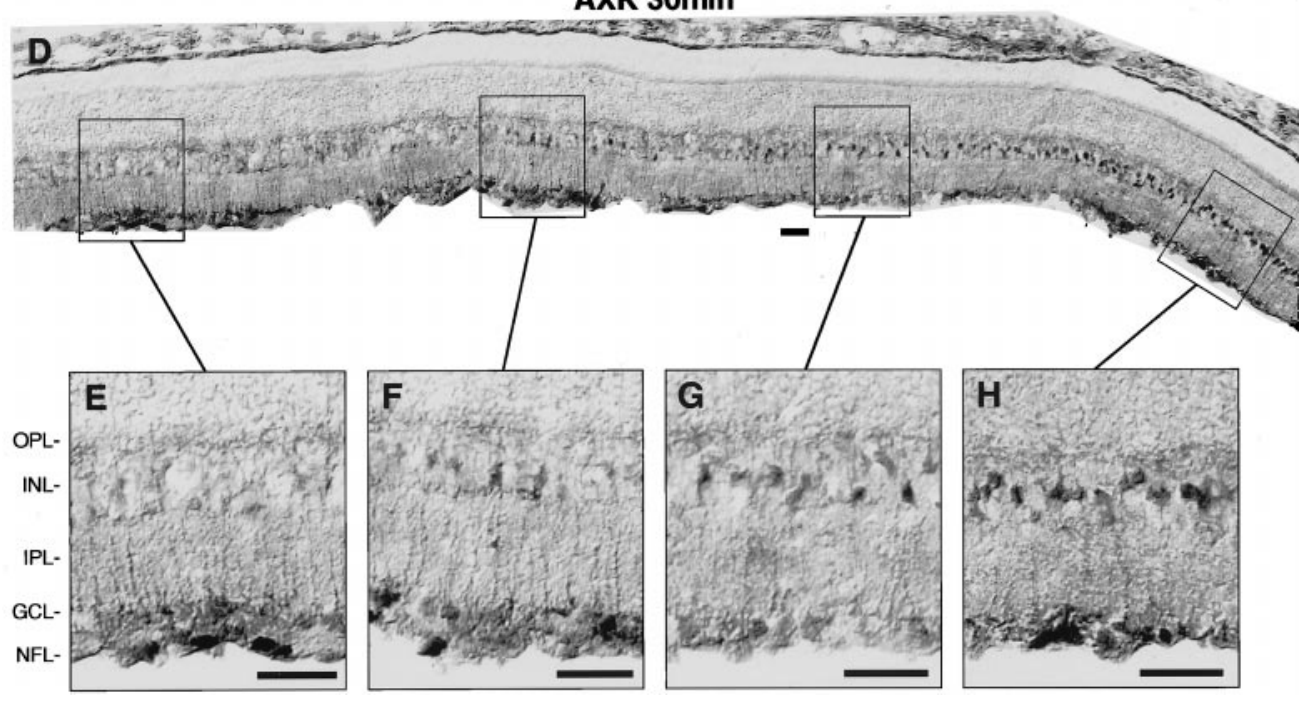

Figure 2. Immunolocalization of total STAT3 in vehicle- and Axokine-treated retinal cross-sections viewed with differential interference contrast optics. $A$, Injection of vehicle $(V E H)$ buffer 15 min before the animals were killed exhibited the same STAT3 labeling pattern as untreated eyes (latter not shown). In the inner retina, diff use labeling of STAT3 was seen along the NFL and GCL, and along radial processes within the IPL and INL (thin arrow). Weak STAT3 immunoreactivity was apparent in the OPL but not in the photoreceptor layer. $B$, Within 15 min of Axokine ( $A X K$ ) injection, we observed intense labeling of nuclei along the NFL (thick arrow), heavier labeling of GC bodies and nuclei (arrowhead), and heavier labeling of cell bodies and nuclei in the INL (thin arrow) near the injection site. $C$, No specific labeling was observed in the absence of primary antibody. $D$, Retinal cross-section taken from four contiguous regions, extending from near the injection site (right half of panel) to further away (left half of panel). E-H, Magnification of boxed regions of $D$ showing spatial profile of STAT3 labeling from regions distal to the injection site $(E)$ to regions closest to the injection site $(H)$. Proximity to the injection site is associated with a progressive increase in STAT3 labeling of cell bodies and nuclei in INL and a concomitant gradual decrease of labeling in processes in the IPL, suggesting mobilization of STAT3 from cytoplasm to cell body, and then to nucleus. Heavy labeling of nuclei in the NFL and GCL is seen throughout the entire region. RPE, Retinal pigment epithelium; OS, photoreceptor outer segments; $I S$, photoreceptor inner segments.

increase in Axokine labeling was observed in this same limited region of the retina (results not shown). In the rest of the retina, total STAT3 immunoreactivity was similar to that of untreated eyes. Our results suggest that the changes in STAT3 labeling occur first in regions proximal to the injection site.

After 30 min of Axokine treatment, a characteristic gradient of total STAT3 labeling was observed within the retina (Fig. 2D). In regions away from the injection site (Fig. 2D, far left, E), we observed dense labeling of nuclei in the nerve fiber layer and some labeling of ganglion cell bodies, with STAT3 labeling in the other retinal layers remaining essentially the same as that found in untreated eyes. However, with increasing proximity to the injection site, we observed a gradual disappearance of labeling of processes in the IPL and a concomitant increase in nuclearspecific immunoreactivity in the INL (Fig. 2D, middle and far right, $F-H)$. At $60 \mathrm{~min}$ after Axokine injection, a consistent labeling pattern for STAT3 was observed throughout the entire retina that is similar to the $30 \mathrm{~min}$ STAT3 labeling near the injection site (results not shown). The STAT3 labeling in the 30 and 60 min vehicle-treated eyes is similar to that of untreated eyes (results not shown). We saw no evidence for STAT3 labeling in photoreceptors under any of our experimental conditions.

\section{Immunolocalization of phosphorylated STAT3}

As early as $15 \mathrm{~min}$ after Axokine injection, heavy labeling of nuclei in the NFL and GCL was observed (Fig. 3B). Vehicletreated retinas exhibited no specific pSTAT3 staining at this time point (Fig. $3 A$ ). pSTAT3 labeling was strongest at the 30 and 60 min time points after Axokine injection and was localized primarily to nuclei in the NFL, GCL, and INL (Fig. 3C-E). Thus, the temporal and spatial labeling profile for pSTAT3 very closely matches that of total STAT3.

pSTAT3 immunoreactivity was observed in the GCL in $4 \mathrm{hr}$ Axokine-treated and vehicle-treated groups (Fig. 3F, G). However, we saw no pSTAT3 labeling in the $16 \mathrm{hr}$ Axokine group (Fig. $3 \mathrm{H})$, despite robust pSTAT3 signal in the immunoblots at $16 \mathrm{hr}$ after Axokine injection. The absence of pSTAT3 labeling at these later time points was not attributable to an artifact in the pro- 
PSTAT3
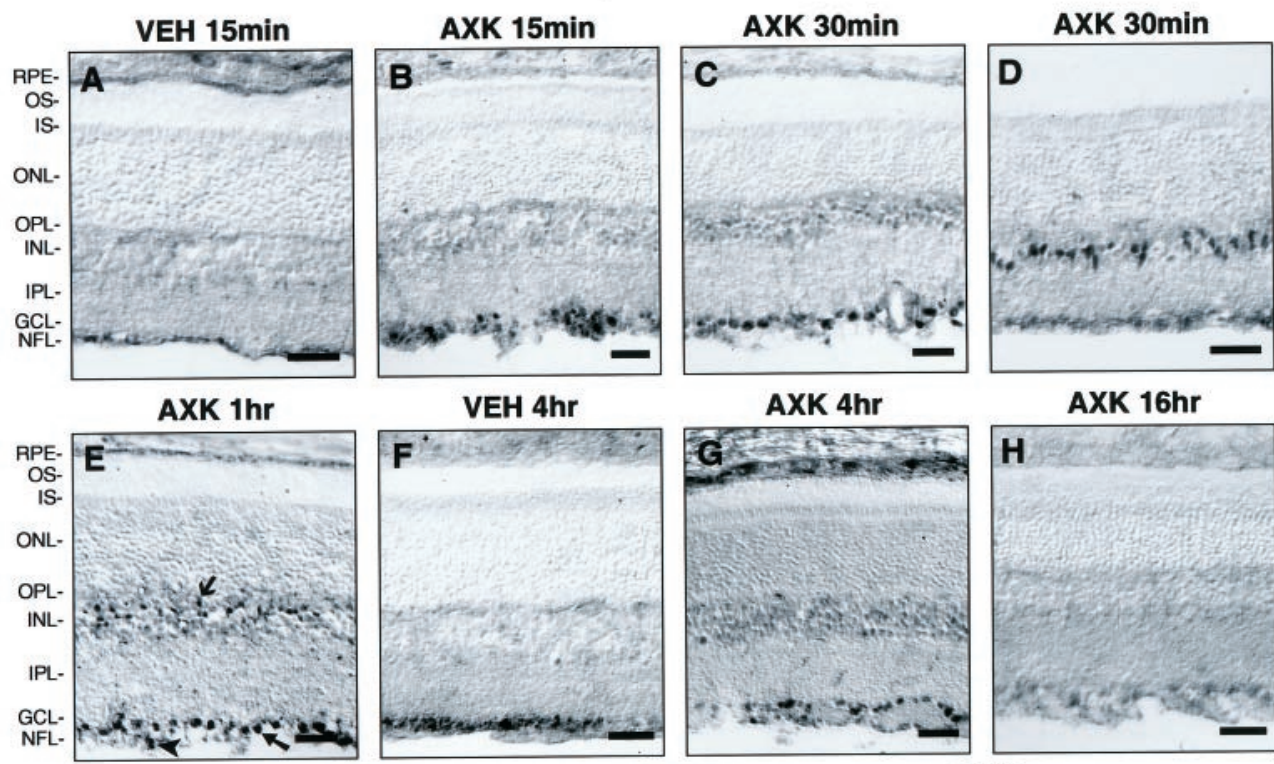

AXK 16hr
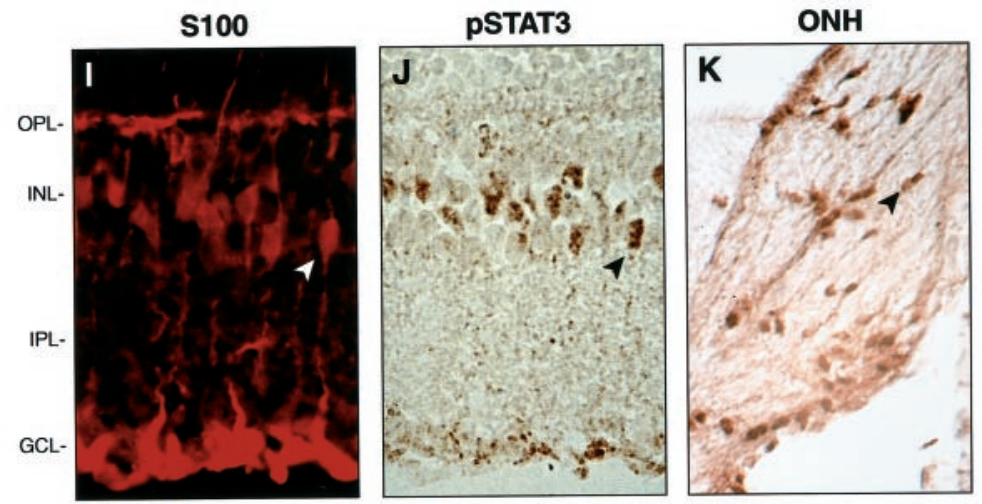

Figure 3. Effects of Axokine on pSTAT3 immunolocalization and colocalization of pSTAT3 and S-100 in Müller cells. $A$, In 15 min vehicle-treated $(V E H)$ eyes, sparse pSTAT3 labeling is present only along the NFL. $B$, Labeling of astrocytes and GC nuclei is observed adjacent to the injection site $15 \mathrm{~min}$ after Axokine $(A X K)$ treatment. $C, D$, Two representative regions of pSTAT3 immunoreactivity in the same retina 30 min after Axokine treatment. $C$, pSTAT3 heavily labeled GC nuclei and weakly labeled nuclei in the INL. $D$, pSTAT3 heavily labeled nuclei in the INL but produced little labeling in GC bodies and nuclei. $E$, At $1 \mathrm{hr}$, strong labeling of nuclei in INL (thin arrow), GCs (thick arrow), and astrocytes (arrowhead) was observed in most of the retina. $F$, A diffuse band of pSTAT3 labeling was evident along the GCL and NFL in vehicle-treated eyes. $G$, pSTAT3 labeling of nuclei in the INL gradually disappeared by $4 \mathrm{hr}$ after Axokine treatment, but signal could still be detected in nuclei within the GCL. $H$, At $16 \mathrm{hr}$ after Axokine injection, no specific pSTAT3 immunoreactivity was detected. $I, J$, One-to-one colocalization of S-100 antigen (left) and pSTAT3 (right) immunoreactivity in the INL is consistent with exclusive localization of STAT3 in Müller cells in the INL. $K$, At $60 \mathrm{~min}$ after Axokine treatment, pSTAT3 immunoreactivity was observed in nuclei of astrocytes throughout the optic nerve head $(O N H)$. RPE, Retinal pigment epithelium; $O S$, photoreceptor outer segments; IS, photoreceptor inner segments. cessing, because positive pSTAT3 controls (i.e., $30 \mathrm{~min}$ or $1 \mathrm{hr}$ Axokine-treated eyes) were run in tandem from the same experimental group of animals, processed with identical immunohistological procedures, and yielded robust pSTAT3 immunoreactivity. These results suggest that, at these later time points, the antigen recognition site on pSTAT3 is not accessible for binding to the antibody in whole, freshly fixed tissues but is accessible under the denaturing conditions of a Western blot (see Discussion).

The results of total STAT3 and pSTAT3 immunostaining studies are consistent with cytoplasmic localization of STAT3 under untreated conditions, followed by phosphorylation and nuclear translocation of pSTAT3 in retinal astrocytes, ganglion cells, and Müller cells after Axokine treatment. To confirm the notion that pSTAT3 labeling in the INL is localized exclusively in Müller cells, we show that pSTAT3 is specifically colocalized with a Müller cell marker, S-100 ( $\beta$-subunit) antigen, in the INL (Fig. $3 I, J)$. In addition, intense nuclei-specific pSTAT3 immunoreactivity was observed in the nuclei of astrocytes distributed along the NFL and optic nerve head (Fig. $3 K$ ) at $1 \mathrm{hr}$ after Axokine injection but not in vehicle-treated eyes.

\section{Immunolocalization of phosphorylated MAPK}

The immunoblots for pMAPK from Figure $1 E$ demonstrated that Axokine treatment also activated p42/44 MAPK. The same
pMAPK antibodies were used to determine cell-specific localization of pMAPK after Axokine or vehicle treatment (Fig. 4). At 30 min after Axokine injection, the regions proximal to the injection site showed intense pMAPK labeling in cells and processes along the ILM, in cells within INL, and in radial processes within the IPL and the outer nuclear layer (ONL) (Fig. 4A). Strong pMAPK staining was also observed surrounding the inner retinal vasculature. This labeling pattern is consistent with distribution of pMAPK in astrocyte and Müller cell processes, cell bodies, and nuclei. By 60 min, pMAPK labeling in Müller cell processes permeated the ONL and distributed along the microvillous extensions along the outer limiting membrane (Fig. 4C). Specific phospho-MAPK labeling in vehicle-treated eyes was very weak and primarily confined to the vicinity of the injection site (Fig. $4 B, D)$. No photoreceptor-specific labeling of pMAPK was observed in either Axokine- or vehicle-treated eyes.

\section{Time course of Axokine-induced GFAP expression in Müller cells}

To compare the time course of Axokine-induced expression of GFAP in Müller cells with that of STAT3 activation, we injected Axokine into the vitreous and processed retinas for GFAP immunohistochemistry $1 \mathrm{hr}$ to 3 weeks later. GFAP is normally localized in astrocytes along the ILM and NFL, and this labeling pattern was unchanged for up to $16 \mathrm{hr}$ after a 

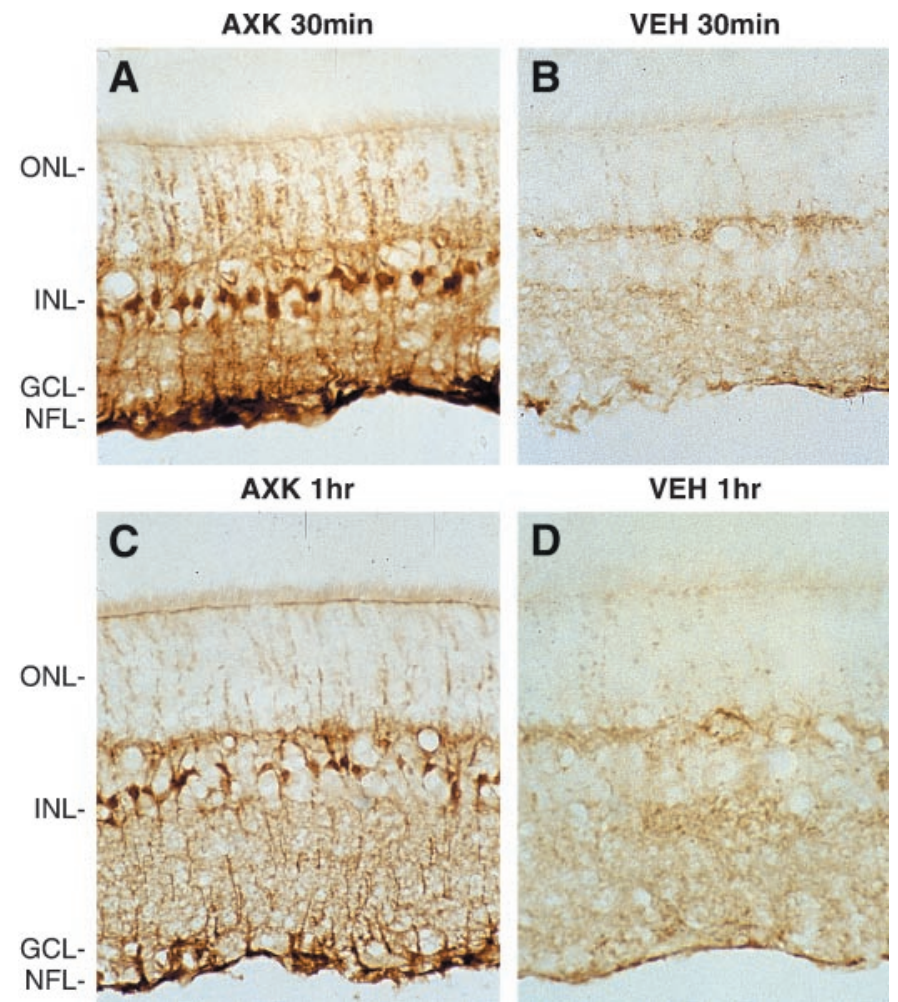

Figure 4. Immunolocalization of pMAPK. $A$, At 30 min after Axokine $(A X K)$ injection, intense pMAPK staining is noted in cells and cell processes in the NFL, particularly surrounding blood vessels, which is consistent with staining of astrocytes. Intense staining of nuclei in the INL and of radial elements extending from the NFL through the ONL is consistent with distribution of pMAPK throughout Müller cell bodies and processes. At this time point, pMAPK staining was strongest in regions nearest the injection site. $B$, Significantly weaker pMAPK staining along the NFL in vehicle-treated $(V E H)$ eyes in regions proximal to the injection site suggests stress-induced activation of MAPK in astrocytes. Very little staining of pMAPK was observed in Müller cells. $C$, Representative photomicrograph of the uniform pMAPK staining apparent within the entire retina at $60 \mathrm{~min}$ after Axokine injection. Note the appearance of pMAPK labeling along the outer limiting membrane. $D$, Very little labeling of pMAPK was observed in $1 \mathrm{hr}$ vehicle-treated eyes.

single vehicle or Axokine injection (Fig. 5). However, after $2 \mathrm{~d}$, the Axokine-treated eyes showed increased labeling of GFAP in Müller cell processes along the IPL. This pattern of GFAP immunoreactivity was most marked at $7 \mathrm{~d}$ after Axokine injection, whereas the contralateral vehicle-treated eyes showed no upregulation or altered distribution of GFAP (Fig. 5). The upregulation of GFAP in Müller cells after Axokine treatment remained strong for at least 3 weeks after the single injection of Axokine, whereas GFAP distribution in contralateral vehicle-treated eyes remained unchanged during this same period (results not shown). These results showing CNTFmediated phosphorylation of STAT3 in Müller cells therefore provide evidence for a direct link between CNTF-mediated STAT3 activation and GFAP expression in the same cell type in vivo.

\section{Effects of stress-mediated stimuli on STAT3}

Exposure to subtoxic bright light for a period of 12-48 hr, followed by $3 \mathrm{~d}$ of normal cyclic lighting, elicits an endogenous neuroprotective response in Sprague Dawley rats that protects photoreceptors from damage upon subsequent exposure to toxic levels of bright light (Liu et al., 1998). We have independently confirmed that this conditioning exposure to bright light does not lead to photoreceptor degeneration (results not shown). In animals that received $24 \mathrm{hr}$ of subtoxic levels of continuous illumination, phosphorylation of STAT3 was observed immediately after termination of the light exposure and persisted for at least $4 \mathrm{~d}$ (Fig. 6A, top two panels). Likewise, robust pSTAT3 was detected for $7 \mathrm{~d}$ after $48 \mathrm{hr}$ of exposure to subtoxic bright light. In both conditioning paradigms, a notable increase in total STAT3 was observed immediately after continuous bright light exposure and persisted several days thereafter. In contrast, lower levels of pSTAT1 were detected after 24 and $48 \mathrm{hr}$ of subtoxic bright light exposure (Fig. 6A, bottom two panels). Nevertheless, a striking increase in total STAT1 was observed in both conditioning paradigms. These results indicate that STAT3 phosphorylation and upregulation of total STAT3 and STAT1 levels occur and persist after a period of conditioning exposure to subtoxic levels of bright light.

Repeated administration of agonists for $\alpha_{2}$-adrenergic receptors, such as xylazine and clonidine, can also protect photoreceptors from light damage (Wen et al., 1996). We observed that anesthetizing rats with ketamine and xylazine phosphorylated STAT3 at $4 \mathrm{hr}$ after the single injection of anesthesia, but the pSTAT3 signal gradually disappeared by $2 \mathrm{~d}$ (Fig. 6B). A similar effect on pSTAT3 was also seen in animals that received xylazine alone, but not in animals that received ketamine alone. We conclude that xylazine alone produces a relatively robust, but short-lived, activation of STAT3.

Mechanical injury to the retina confers protection of photoreceptors surrounding the site of injury from the damaging effects of prolonged exposure to bright light. It has been shown that the retina undergoes a variety of subcellular and biochemical changes in response to trauma and injury, including upregulation of basic FGF, CNTF, GFAP, and c-fos (Wen et al., 1995; Yoshida et al., 1995). We induced mechanical trauma by producing a small injury in the superior retina $\sim 2 \mathrm{~mm}$ from the limbus by inserting a 30 gauge needle through the sclera. We then sectioned the eye 1 week later to examine GFAP, pSTAT3, and total STAT3 labeling near and far from the site of trauma. Increased GFAP and total STAT3 labeling was observed at and near the site of injury and surrounded the region of trauma, but GFAP and STAT3 labeling remained relatively normal at regions of the retina distal from the site of injury (Fig. 7). pSTAT3 labeling was not significantly above background levels (results not shown). These results clearly demonstrate a dramatic increase in cellular STAT3 expression near and surrounding the site of injury.

\section{DISCUSSION}

The present study demonstrates that the Jak-STAT signaling pathway is activated in adult rat retina in response to an intravitreal injection of Axokine, an analog of CNTF. In addition, intraperitoneal delivery of the $\alpha_{2}$-agonist xylazine, exposure to nondamaging bright light, and mechanical injury to the retina also produce a similar response. All four of these stimuli have been shown to protect retinal photoreceptors from the damaging effects of exposure to prolonged periods of bright light (LaVail et al., 1992; Wen et al., 1996; Liu et al., 1998). We also show that Axokine activates p44/42 MAPK, which confirms previous work demonstrating the involvement of ras-MAPK signaling in response to neuronal stress and subsequent cell survival (Segal and Greenberg, 1996; Fukunaga and Miyamoto, 1998). Pronounced upregulation of endogenous, nonphosphorylated STAT3 and 


\section{GFAP}
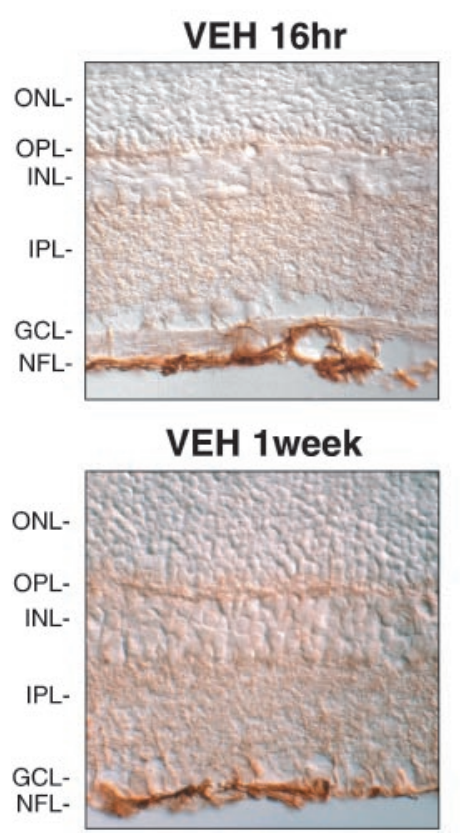

AXK 16hr

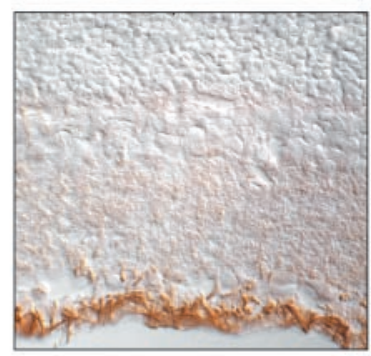

AXK 1week

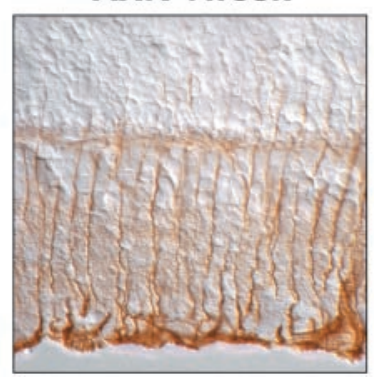

AXK 2day

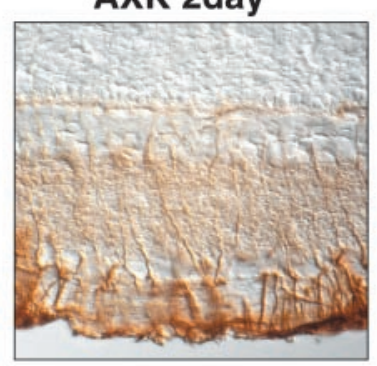

AXK 2week

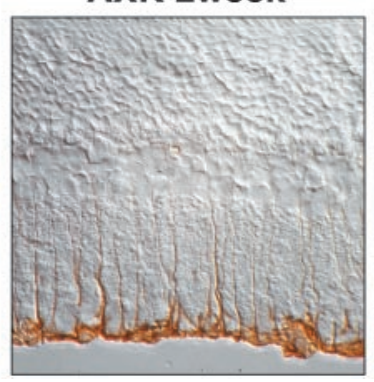

AXK 4day

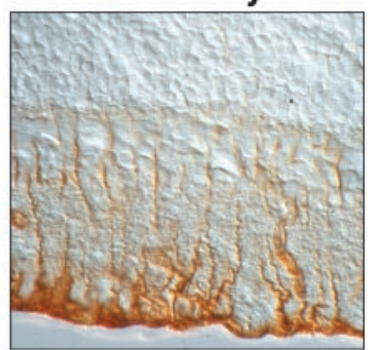

AXK 3week

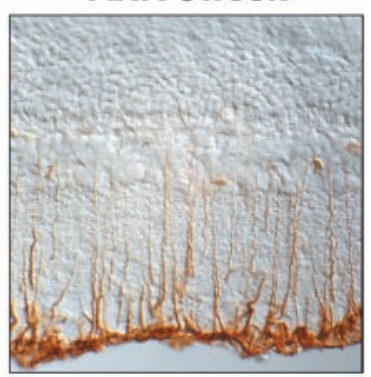

Figure 5. Time course of Axokine-induced expression of GFAP in Müller cells. At $16 \mathrm{hr}$, vehicle-injected $(V E H)$ and Axokine-injected $(A X K)$ retinas still showed essentially normal GFAP labeling, restricted to astrocyte processes and end feet of Müller cells along the NFL and surrounding blood vessels. At $2 \mathrm{~d}$ after Axokine injection, GFAP labeled radial processes in the IPL. At $7 \mathrm{~d}$, labeling of processes throughout the IPL and into the ONL was observed in Axokine-treated eyes but not vehicle-treated eyes. Labeling of radial processes throughout the IPL persisted for at least 3 weeks after Axokine treatment.

STAT1 protein was observed at later time points after Axokine treatment or after exposure (24-48 hr) to elevated levels of ambient light. These results suggest a secondary phase of responsiveness, mediated by both STAT3 and STAT1. The timing of this second phase coincides closely with Axokine-induced upregulation of GFAP in Müller cells. Immunocytochemical studies demonstrate that Axokine produces rapid, persistent activation of STAT3 in retinal Müller cells, astrocytes, and retinal ganglion cells. Although CNTF and these stress-evoked stimuli all protect photoreceptors from environmental insult, we saw no evidence for activation of STAT3 or MAPK in the photoreceptors themselves.

\section{Localization of STAT3 and pSTAT3: relationship to CNTFR $\alpha$ and time course}

In mature rat retina, $\mathrm{CNTFR} \alpha$ mRNA is found in horizontal cells and subpopulations of amacrine and ganglion cells (Kirsch et al., 1997). Here we show that, although Axokine activates STAT3 in retinal ganglion cells, it also activates STAT3 in Müller (glial) cells and astrocytes, which do not appear to express CNTFR $\alpha$. Conversely, we saw no evidence for STAT3 activation in horizontal and amacrine cells. A possible mechanism for CNTF-mediated signaling in retinal glial cells may involve rapid, CNTF-mediated release of CNTFR $\alpha$ from the plasma membrane of horizontal, amacrine, and ganglion cells, and subsequent activation of the CNTF tripartite receptor complex in Müller cells and astrocytes. The localization of LIFR $\beta$ and gp130 in the retina is currently not known. Our findings nevertheless demonstrate that CNTF-mediated STAT3 signaling is not necessarily restricted to cells that express appreciable levels of CNTFR $\alpha$ and that cells that express CNTFR $\alpha$ mRNA do not invariably respond to CNTF. These observations support the hypothesis that
CNTFR $\alpha$ may serve as soluble mediator of the effects of CNTF in vivo (Davis et al., 1993).

Within $30 \mathrm{~min}$, Axokine administration resulted in phosphorylation of STAT3 and a redistribution of STAT3 from the cytoplasm to the nucleus in Müller cells, astrocytes, and ganglion cells. After $1 \mathrm{hr}$, nuclei-specific pSTAT3 staining began to diminish. After $4 \mathrm{hr}$, pSTAT3-positive cells were restricted to the ganglion cell layer in Axokine-treated and vehicle-treated eyes. At $16 \mathrm{hr}$ in Axokine-treated eyes, pSTAT3-specific immunolabeling disappeared, although strong total pSTAT3 signal was observed in immunoblots. The disparity between pSTAT3 immunoblot and immunostaining at the later time points raises the possibility that the antibody recognition site for pSTAT3 is occluded by associated protein(s) at some point after its translocation to the nucleus. Recent work has shown that PIAS3, a member of the protein inhibitor of activated STAT, specifically binds to phosphorylated STAT3 and inactivates STAT3-mediated gene transcription (Chung et al., 1997). Protein-protein interaction between PIAS3 and the Y705-phosphorylated site of STAT3 may therefore account for the absence of pSTAT3-specific labeling in aldehyde-fixed tissue sections.

\section{Specificity of STAT3 verses STAT1 and relationship to MAPK}

CNTF-mediated stimulation of STAT1 and STAT3 in neural precursor and neuroepithelial stem cells promotes their differentiation into astrocytes (Rajan et al., 1996; Bonni et al., 1997; Rajan and McKay, 1998). In stable, differentiated cells lines, such as COS or HeLa, CNTF preferentially phosphorylates STAT3 rather than STAT1 (Boulton et al., 1995; Stahl et al., 1995). The preferential activation of STAT3 by CNTF has been attributed to alterations in modular tyrosine-based motifs in cytokine recep- 


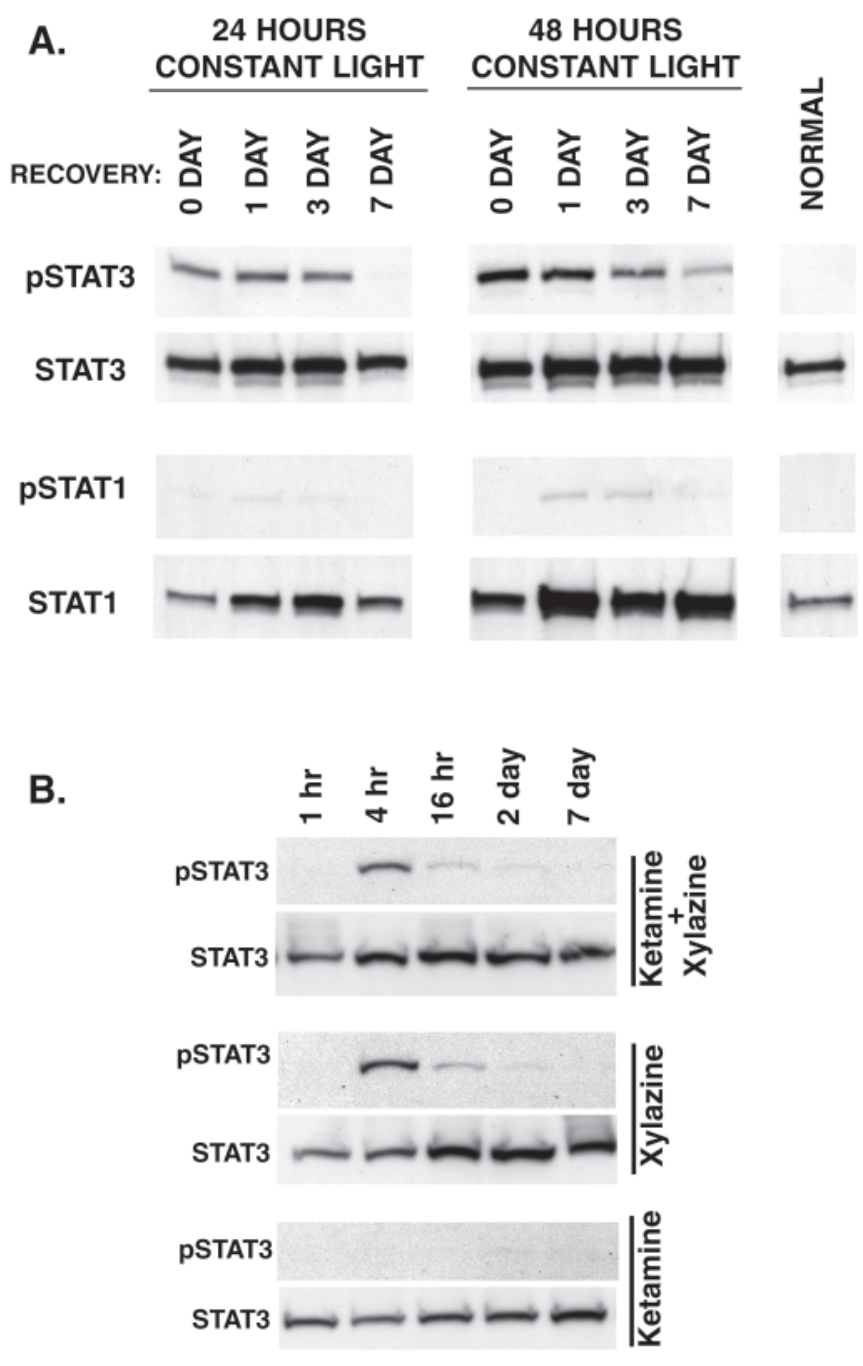

Figure 6. Activation of STAT3 and/or STAT1 after conditioning with 24 or $48 \mathrm{hr}$ of bright light or treatment with various combinations of ketamine and xylazine. In $A$, animals were recovered in normal lighting conditions for the time periods shown before retinas were harvested for immunoblotting. $A$, STAT3 was activated immediately after 24 or $48 \mathrm{hr}$ of constant bright light (day 0). An increase in total STAT3 levels was also observed in both conditioning groups. Twenty-four and $48 \mathrm{hr}$ of bright light produced a small, delayed increase in pSTAT1 signal during the recovery period and a robust increase in total STAT1 levels. $B$, Effects of various combinations of ketamine and xylazine (intraperitoneal injection) on pSTAT3 and total STAT3 signal in retina. Xylazine alone or in combination with ketamine produced a robust phosphorylation of STAT3 $4 \mathrm{hr}$ after administration. No activation of STAT3 was observed in the ketamine group.

tors (Stahl et al., 1995). Our results indicate that Axokine predominantly activates STAT3 rather than STAT1 in the mature retina and support the notion that STAT3 is the primary effector protein of CNTF-mediated Jak-STAT signaling. A secondary signaling event, perhaps mediated by STAT3 feedback to STAT1, may be responsible for the delayed and weaker CNTF-mediated phosphorylation of STAT1 and subsequent robust increases in total STAT1 and STAT3 proteins.

CNTF-mediated activation of MAPK occurs after STAT3 activation in retina. Cytokine-induced stimulation of MAPK is proposed to occur via recruitment of Src homology 2 phosphatase (SHP2) to tyrosine-phosphorylated gp130, interaction between
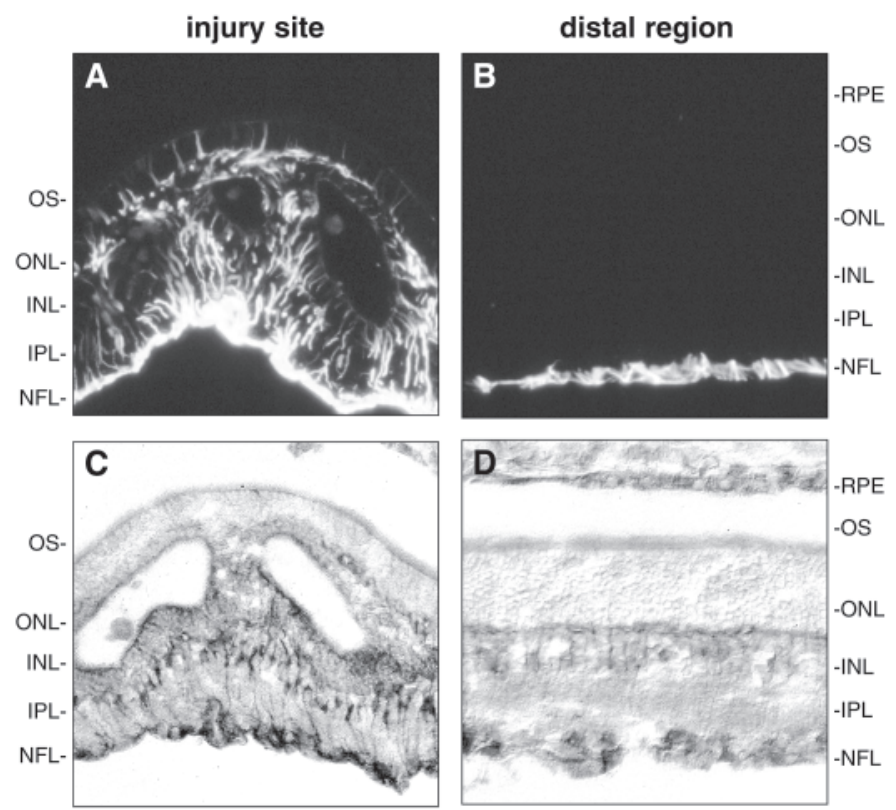

Figure 7. Needle injury to the retina induces GFAP upregulation and increases total STAT3 labeling around the injury site. $A$, Fluorescent photomicrograph of robust GFAP-positive processes in the GCL (which borders the inner limiting membrane) and throughout the retina encompassing the region of trauma. $B$, GFAP labeling in the same eye in a region of the retina that is far from the site of injury. Normal GFAPpositive labeling in the region between the GCL and the ILM is observed. $C$, In a representative section from the same region as $A$, increased STAT3 signal is detected along ILM, the GCL, and radial processes in the IPL, as well as cell bodies and nuclei in the INL. $D$, In a representative section from the same region as $B$, STAT3 immunoreactivity in regions far from the injection site is similar to that of unperturbed retinas. RPE, Retinal pigment epithelium; $O S$, photoreceptor outer segments.

SHP-2 and membrane-associated Ras, and subsequent stimulation of ras-MAPK signaling (Chin et al., 1997; Kim and Baumann, 1999). Activation of MAPK by CNTF treatment has also been observed in neural precursors in vitro in which it is proposed to also influence GFAP expression via STAT-dependent and STAT-independent mechanisms (Bonni et al., 1997; Rajan and McKay, 1998). MAPK activation can downregulate STAT3mediated transcription by blocking tyrosine phosphorylation of STAT3 and by phosphorylating STAT3 at serine residues (Jain et al., 1998; Sengupta et al., 1998). Previous work has shown that the ras-MAPK pathway is activated in Müller cells by exposure to bright light and administration of xylazine (Liu et al., 1998; Peng et al., 1998). Our results suggest that Jak-STAT signaling in retinal glial cells can be influenced by cross-talk with the rasMAPK pathway and that both pathways are likely involved in mediating the effects of CNTF in promoting neuronal survival in the retina and elsewhere.

\section{A link between CNTF, Jak-STAT, GFAP, and neuroprotection in vivo}

Cytosolic CNTF is released into the extracellular environment after trauma (Friedman et al., 1992; Sendtner et al., 1992; Stahl and Yancopoulos, 1994). In adult rat retina, CNTF is localized along Müller cell processes (Kirsch et al., 1997). Therefore, CNTF release from damaged Müller cells after local physical trauma may be responsible for STAT3 activation in nearby, intact Müller cells. However, it is unknown whether CNTF is also released and therefore involved in the activation of STAT3 after 
conditioning exposure to bright light or stimulation of $\alpha_{2^{-}}$ adrenergic receptors by xylazine. Recent work has implicated the involvement of Jak-STAT signaling in multiple physiological processes in the nervous system (Bonni et al., 1997; Rajan and McKay, 1998). In vitro studies have shown that STAT3 activation permits astrocytic differentiation from precursor cells, induces neurite outgrowth in PC12 cells, and produces dendritic retraction in cultured sympathetic neurons (Wu and Bradshaw, 1996; Ihara et al., 1997; Guo et al., 1999). STAT3 is phosphorylated in vivo in neurons in the rat superior cervical ganglion after transection of the postganglion nerves, in microglia after transient focal cerebral ischemia, and in cortical glia after excitotoxic lesions (Rajan et al., 1995; Planas et al., 1996; Acarin et al., 1998). These findings suggest a role for STAT3 in response to neuronal stress. Whether STAT3 activation in response to stress is sufficient to promote neuronal survival is unknown, but the present study demonstrates that exogenously administered CNTF can directly activate STAT3 in vivo. Given the documented neuroprotective effects of CNTF in the CNS and peripheral nervous system, our findings support the direct involvement of the JakSTAT pathway in mediating survival of mature neurons.

CNTF-mediated activation of STAT1 and STAT3 can specify cortical precursors and neuroepithelial stem cells in vitro to adopt an astrocyte phenotype by binding to the gfap promoter and stimulating GFAP expression (Bonni et al., 1997; Rajan and McKay, 1998). Exogenously administered CNTF and a wide variety of stress-mediated stimuli induce dramatic upregulation of GFAP in CNS astrocytes and retinal Müller cells (Eisenfeld et al., 1984; Guerin et al., 1990; de Raad et al., 1996; Chu et al., 1998; Milam et al., 1998). Our results are the first to show a direct link between CNTF-mediated early activation of STAT3 in vivo and the subsequent upregulation of GFAP in the same glial cells. These findings indicate that CNTF can directly act on glia, despite the fact that they appear to express little or no CNTFR $\alpha$ mRNA or protein in the intact retina and CNS (Ip et al., 1993; MacLennan et al., 1996; Kirsch et al., 1997; Fuhrmann et al., 1998).

Given the early STAT3 responsiveness of retinal ganglion cells to CNTF, activation of the Jak-STAT signaling pathway may directly mediate the neuroprotective effects of CNTF on ganglion cells (Unoki and LaVail, 1994; Cui et al., 1999). However, CNTF did not activate STAT3 in photoreceptors. In this context, it is interesting to note that CNTF or Axokine must be administered 24-48 hr before exposure to toxic levels of light to maximally protect photoreceptors from damage (M. LaVail, personal communications). This temporal lag coincides closely with the Axokine-induced upregulation of GFAP in Müller cells and the delayed upregulation of total STAT1 and STAT3 levels. Recent work has shown that the presence of GFAP-positive, "reactive" astrocytes is associated with protection of neurons from extensive degeneration caused by localized stab-induced injury (Bush et al., 1999). It is unknown how "activated" astrocytes support neuronal survival. Our present results strongly suggest that CNTF-mediated changes in Müller cell function initiate a secondary, neuroprotective signaling event to photoreceptors, the nature of which remains to be elucidated.

\section{REFERENCES}

Acarin L, Gonzalez B, Castellano B (1998) Stat3 and NF $\kappa$ B glial expression after excitotoxic damage to the postnatal brain. NeuroReport 9:2869-2873.

Adler R, Landa KB, Manthorpe M, Varon S (1979) Cholinergic neu- ronotrophic factors: intraocular distribution of trophic activity for ciliary neurons. Science 204:1434-1436.

Anderson KD, Panayotatos N, Corcoran TL, Lindsay RM, Wiegand SJ (1996) Ciliary neurotrophic factor protects striatal output neurons in an animal model of Huntington disease. Proc Natl Acad Sci USA 93:7346-7351.

Bonni A, Frank DA, Schindler C, Greenberg ME (1993) Characterization of a pathway for ciliary neurotrophic factor signaling to the nucleus. Science 262:1575-1579.

Bonni A, Sun Y, Nadal-Vicens M, Bhatt A, Frank DA, Rozovsky I, Stahl N, Yancopoulos GD, Greenberg ME (1997) Regulation of gliogenesis in the central nervous system by the JAK-STAT signaling pathway. Science 278:477-483.

Boulton TG, Zhong Z, Wen Z, Darnell Jr JE, Stahl N, Yancopoulos GD (1995) STAT3 activation by cytokines utilizing gp130 and related transducers involves a secondary modification requiring an $\mathrm{H} 7-$ sensitive kinase. Proc Natl Acad Sci USA 92:6915-6919.

Bush TG, Puvanachandra N, Horner CH, Polito A, Ostenfeld T, Svendsen CN, Mucke L, Johnson MH, Sofroniew MV (1999) Leukocyte infiltration, neuronal degeneration, and neurite outgrowth after ablation of scar-forming, reactive astrocytes in adult transgenic mice. Neuron 23:297-308.

Cao W, Wen R, Li F, Lavail MM, Steinberg RH (1997) Mechanical injury increases bFGF and CNTF mRNA expression in the mouse retina. Exp Eye Res 65:241-248.

Chin YE, Kitagawa M, Kuida K, Flavell RA, Fu XY (1997) Activation of the STAT signaling pathway can cause expression of caspase 1 and apoptosis. Mol Cell Biol 17:5328-5337.

Chu Y, Humphrey MF, Alder VV, Constable IJ (1998) Immunocytochemical localization of basic fibroblast growth factor and glial fibrillary acidic protein after laser photocoagulation in the Royal College of Surgeons rat. Aust N Z J Ophthalmol 26:87-96.

Chung CD, Liao J, Liu B, Rao X, Jay P, Berta P, Shuai K (1997) Specific inhibition of Stat3 signal transduction by PIAS3. Science 278:1803-1805.

Cui Q, Lu Q, So KF, Yip HK (1999) CNTF, not other trophic factors, promotes axonal regeneration of axotomized retinal ganglion cells in adult hamsters. Invest Ophthalmol Vis Sci 40:760-766.

Darnell Jr JE, Kerr IM, Stark GR (1994) Jak-STAT pathways and transcriptional activation in response to IFNs and other extracellular signaling proteins. Science 264:1415-1421.

Davis S, Aldrich TH, Ip NY, Stahl N, Scherer S, Farruggella T, DiStefano PS, Curtis R, Panayotatos N, Gascan H, Chevalier S, Yancopoulos GD (1993) Released form of CNTF receptor alpha component as a soluble mediator of CNTF responses. Science 259:1736-1739.

de Raad S, Szczesny PJ, Munz K, Reme CE (1996) Light damage in the rat retina: glial fibrillary acidic protein accumulates in Muller cells in correlation with photoreceptor damage. Ophthalmic Res 28:99-107.

Eisenfeld AJ, Bunt-Milam AH, Sarthy PV (1984) Muller cell expression of glial fibrillary acidic protein after genetic and experimental photoreceptor degeneration in the rat retina. Invest Ophthalmol Vis Sci 25:1321-1328.

Friedman B, Scherer SS, Rudge JS, Helgren M, Morrisey D, McClain J, Wang DY, Wiegand SJ, Furth ME, Lindsay RM, Ip NY (1992) Regulation of ciliary neurotrophic factor expression in myelin-related Schwann cells in vivo. Neuron 9:295-305.

Fuhrmann S, Kirsch M, Heller S, Rohrer H, Hofmann HD (1998) Differential regulation of ciliary neurotrophic factor receptor-alpha expression in all major neuronal cell classes during development of the chick retina. J Comp Neurol 400:244-254.

Fukunaga K, Miyamoto E (1998) Role of MAP kinase in neurons. Mol Neurobiol 16:79-95.

Guerin CJ, Anderson DH, Fisher SK (1990) Changes in intermediate filament immunolabeling occur in response to retinal detachment and reattachment in primates. Invest Ophthalmol Vis Sci [Erratum (1990) 31:2360] 31:1474-1482.

Guo X, Chandrasekaran V, Lein P, Kaplan PL, Higgins D (1999) Leukemia inhibitory factor and ciliary neurotrophic factor cause dendritic retraction in cultured rat sympathetic neurons. J Neurosci 19:2113-2121.

Hagg T, Varon S (1993) Ciliary neurotrophic factor prevents degeneration of adult rat substantia nigra dopaminergic neurons in vivo. Proc Natl Acad Sci USA 90:6315-6319.

Ihara S, Nakajima K, Fukada T, Hibi M, Nagata S, Hirano T, Fukui Y 
(1997) Dual control of neurite outgrowth by STAT3 and MAP kinase in PC12 cells stimulated with interleukin-6. EMBO J 16:5345-5352.

Ip NY, McClain J, Barrezueta NX, Aldrich TH, Pan L, Li Y, Wiegand SJ, Friedman B, Davis S, Yancopoulos GD (1993) The $\alpha$ component of the CNTF receptor is required for signaling and defines potential CNTF targets in the adult and during development. Neuron 10:89-102.

Jain N, Zhang T, Fong SL, Lim CP, Cao X (1998) Repression of Stat3 activity by activation of mitogen-activated protein kinase (MAPK). Oncogene 17:3157-3167.

Ju WK, Lee MY, Hofmann HD, Kirsch M, Chun MH (1999) Expression of CNTF in Muller cells of the rat retina after pressure-induced ischemia. NeuroReport 10:419-422.

Kim H, Baumann H (1999) Dual signaling role of the protein tyrosine phosphatase SHP-2 in regulating expression of acute-phase plasma proteins by interleukin-6 cytokine receptors in hepatic cells. Mol Cell Biol 19:5326-5338.

Kirsch M, Hofmann HD (1994) Expression of ciliary neurotrophic factor receptor mRNA and protein in the early postnatal and adult rat nervous system. Neurosci Lett 180:163-166.

Kirsch M, Lee MY, Meyer V, Wiese A, Hofmann HD (1997) Evidence for multiple, local functions of ciliary neurotrophic factor (CNTF) in retinal development: expression of $\mathrm{CNTF}$ and its receptors and in vitro effects on target cells. J Neurochem 68:979-990.

LaVail MM, Unoki K, Yasumura D, Matthes MT, Yancopoulos GD, Steinberg RH (1992) Multiple growth factors, cytokines, and neurotrophins rescue photoreceptors from the damaging effects of constant light. Proc Natl Acad Sci USA 89:11249-11253.

Lin LF, Mismer D, Lile JD, Armes LG, Butler III ET, Vannice JL, Collins F (1989) Purification, cloning, and expression of ciliary neurotrophic factor (CNTF). Science 246:1023-1025.

Liu C, Peng M, Laties AM, Wen R (1998) Preconditioning with bright light evokes a protective response against light damage in the rat retina. J Neurosci 18:1337-1344.

MacLennan AJ, Vinson EN, Marks L, McLaurin DL, Pfeifer M, Lee N (1996) Immunohistochemical localization of ciliary neurotrophic factor receptor alpha expression in the rat nervous system. J Neurosci 16:621-630.

Mattson MP, Scheff SW (1994) Endogenous neuroprotection factors and traumatic brain injury: mechanisms of action and implications for therapy. J Neurotrauma 11:3-33.

Milam AH, Li ZY, Fariss RN (1998) Histopathology of the human retina in retinitis pigmentosa. Prog Retin Eye Res 17:175-205.

Negro A, Corsa V, Corona G, Grandi C, Skaper SD, Callegaro L (1994) Structure-function studies of human ciliary neurotrophic factor. Neurochem Res 19:223-227.

Panayotatos N, Radziejewska E, Acheson A, Pearsall D, Thadani A, Wong V (1993) Exchange of a single amino acid interconverts the specific activity and gel mobility of human and rat ciliary neurotrophic factors. J Biol Chem 268:19000-19003.

Peng M, Li Y, Luo Z, Liu C, Laties AM, Wen R (1998) Alpha2adrenergic agonists selectively activate extracellular signal-regulated kinases in Muller cells in vivo. Invest Ophthalmol Vis Sci 39:1721-1726.

Planas AM, Soriano MA, Berruezo M, Justicia C, Estrada A, Pitarch S, Ferrer I (1996) Induction of Stat3, a signal transducer and transcription factor, in reactive microglia following transient focal cerebral ischaemia. Eur J Neurosci 8:2612-2618.
Rajan P, McKay RD (1998) Multiple routes to astrocytic differentiation in the CNS. J Neurosci 18:3620-3629.

Rajan P, Stewart CL, Fink JS (1995) LIF-mediated activation of STAT proteins after neuronal injury in vivo. NeuroReport 6:2240-2244.

Rajan P, Symes AJ, Fink JS (1996) STAT proteins are activated by ciliary neurotrophic factor in cells of central nervous system origin. J Neurosci Res 43:403-411.

Segal RA, Greenberg ME (1996) Intracellular signaling pathways activated by neurotrophic factors. Annu Rev Neurosci 19:463-489.

Sendtner M, Stockli KA, Thoenen H (1992) Synthesis and localization of ciliary neurotrophic factor in the sciatic nerve of the adult rat after lesion and during regeneration. J Cell Biol 118:139-148.

Sendtner M, Carroll P, Holtmann B, Hughes RA, Thoenen H (1994) Ciliary neurotrophic factor. J Neurobiol 25:1436-1453.

Sengupta TK, Talbot ES, Scherle PA, Ivashkiv LB (1998) Rapid inhibition of interleukin-6 signaling and Stat 3 activation mediated by mitogen-activated protein kinases. Proc Natl Acad Sci USA 95:11107-11112.

Stahl N, Yancopoulos GD (1994) The tripartite CNTF receptor complex: activation and signaling involves components shared with other cytokines. J Neurobiol 25:1454-1466.

Stahl N, Boulton TG, Farruggella T, Ip NY, Davis S, Witthuhn BA, Quelle FW, Silvennoinen O, Barbieri G, Pellegrini S, Ihle IN, Yancopoulos GD (1994) Association and activation of Jak-Tyk kinases by CNTF-LIF-OSM-IL-6 beta receptor components. Science 263:92-95.

Stahl N, Farruggella TJ, Boulton TG, Zhong Z, Darnell Jr JE, Yancopoulos GD (1995) Choice of STATs and other substrates specified by modular tyrosine- based motifs in cytokine receptors. Science 267:1349-1353.

Stockli KA, Lottspeich F, Sendtner M, Masiakowski P, Carroll P, Gotz R, Lindholm D, Thoenen H (1989) Molecular cloning, expression and regional distribution of rat ciliary neurotrophic factor. Nature 342:920-923.

Unoki K, LaVail MM (1994) Protection of the rat retina from ischemic injury by brain-derived neurotrophic factor, ciliary neurotrophic factor, and basic fibroblast growth factor. Invest Ophthalmol Vis Sci 35:907-915.

Wegenka UM, Buschmann J, Lutticken C, Heinrich PC, Horn F (1993) Acute-phase response factor, a nuclear factor binding to acute-phase response elements, is rapidly activated by interleukin-6 at the posttranslational level. Mol Cell Biol 13:276-288.

Wen R, Song Y, Cheng T, Matthes MT, Yasumura D, LaVail MM, Steinberg RH (1995) Injury-induced upregulation of bFGF and CNTF mRNAS in the rat retina. J Neurosci 15:7377-7385.

Wen R, Cheng T, Li Y, Cao W, Steinberg RH (1996) Alpha 2adrenergic agonists induce basic fibroblast growth factor expression in photoreceptors in vivo and ameliorate light damage. J Neurosci 16:5986-5992.

Wu YY, Bradshaw RA (1996) Induction of neurite outgrowth by interleukin-6 is accompanied by activation of Stat 3 signaling pathway in a variant PC12 cell (E2) line. J Biol Chem 271:13023-13032.

Yoshida K, Muraki Y, Ohki K, Harada T, Ohashi T, Matsuda H, Imaki J (1995) C-fos gene expression in rat retinal cells after focal retinal injury. Invest Ophthalmol Vis Sci 36:251-254. 